\title{
A CASE OF PAROXYSMAL SUPRAVENTRICULAR TACHYCARDIA IN INFANCY TREATED WITH PROCAINE AMIDE
}

\author{
BY
}

\author{
N. SHER
}

From the Booth Hall Children's Hospital, Manchester

Paroxysmal rapid heart action in infancy is not common. The condition is sometimes difficult to recognize as it may be symptomless or may only be detected during examination for a complaint unconnected with the cardiovascular system. However, its recognition is important because the response to therapy is satisfactory and may, on occasion, be life-saving. The following case is reported to illustrate this.

A male infant, aged 2 months, was admitted to Booth Hall Hospital, Manchester, with a two-day history of fever, coryza, and cough. The infant had been born with asphyxia livida due to the cord round the neck but resuscitation was successful. He was not breast-fed and thrived on a dried milk formula.

On examination he was a well nourished infant, apyrexial but very dyspnœic with a respiratory rate of 60 a minute. There was no cyanosis or oedema. The pulse and heart rate seemed too fast to count with accuracy. The liver at this stage was not palpable and a diagnosis of upper respiratory infection was made. During the next day, the infant's condition deteriorated and signs of cardiac failure became evident, with cyanosis, congestion of the neck veins, peripheral œdema, and enlargement of the liver to four finger breadths below the costal margin. The heart rate was still difficult to count and a diagnosis of paroxysmal tachycardia with cardiac failure was made.

An injection of $50 \mathrm{mg}$. of procaine amide hydrochloride (pronestyl) was given intravenously and the heart rate fell immediately to 168 a minute but in the next eight hours the rate rose again and once more became uncountable. A further intravenous injection of $50 \mathrm{mg}$. pronestyl was given, but on this occasion it had no effect. Digoxin $\mathbf{0 . 2 5} \mathrm{mg}$. was then given orally and within two hours a decided improvement in the infant's condition was noted, and in four hours the heart rate was reduced to 180 a minute. The digoxin was continued orally four-hourly in the same dosage for the next 24 hours. By this time the cyanosis and odema had gone and the liver edge was just palpable below the costal margin, the heart rate being 140 . The dose of digoxin was then reduced to $0.125 \mathrm{mg}$. eight-hourly, and the pulse gradually fell to 98 a minute. After a further four days the digoxin was discontinued. An electrocardiogram taken at the end of the treatment showed a regular rate of 125 with a P-R interval of $0.08 \mathrm{sec}$. and a QRS duration of $0.06 \mathrm{sec}$. All waves were of normal configuration and the infant was discharged well after a further 14 days.

However, four months later he was readmitted, now aged six months, with a history of breathlessness, oliguria, and vomiting for 24 hours. On examination cyanosis and dyspnœea were noted. There was no œedema, and the liver was once again palpable four finger breadths below the costal margin and once again the heart rate was very fast and estimated to be over 200 a minute. Paroxysmal tachycardia was diagnosed and an electrocardiogram was taken (Fig. 1) which showed a regular heart rate of 270. The $P$ waves were upright in the standard leads and there was a short $P-R$ interval of $0.08 \mathrm{sec}$. and a short QRS duration of $0.05 \mathrm{sec}$., confirming the diagnosis of supraventricular paroxysmal tachycardia of sinus origin. An X-ray also showed enlargement of the cardiac silhouette.

A dose of $50 \mathrm{mg}$. of procaine amide hydrochloride (pronestyl) was then injected into the superior sagittal sinus. The heart rate was immediately reduced to 230 but 20 minutes later it was uncountable again. After 3 hours the infant's condition was much worse and a further $75 \mathrm{mg}$. pronestyl was given intravenously with an immediate reduction of the heart rate to 144 a minute. The pulse rate continued to fall and three hours after the second injection it was 120 and 12 hours later was 100 . The rate remained between 100-120 without further treatment. The child's condition improved rapidly, the cyanosis and signs of congestive failure disappeared six hours after the last injection of pronestyl. The liver gradually receded and two days after treatment was one finger breadth below the costal margin. An electrocardiogram (Fig. 2) taken 12 hours after the second dose of pronestyl showed the heart rate to be 130 but the $P$ waves, $P-R$ interval, and QRS interval were unchanged. The infant continued to be well till his discharge seven days after admission, and during the past six months had had no further paroxysms. 


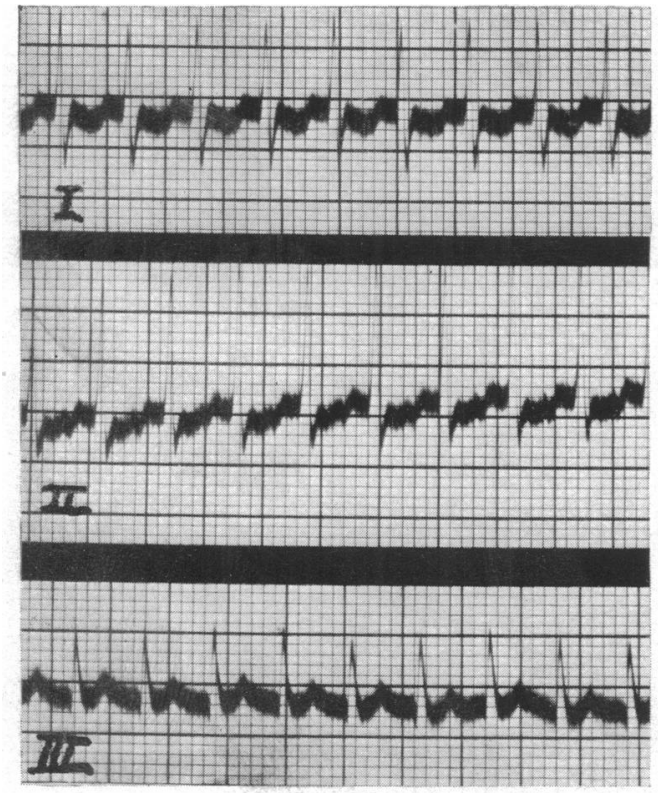

FIG. 1.-Electrocardiogram showing paroxysmal tachycardia, rate 270 a minute.

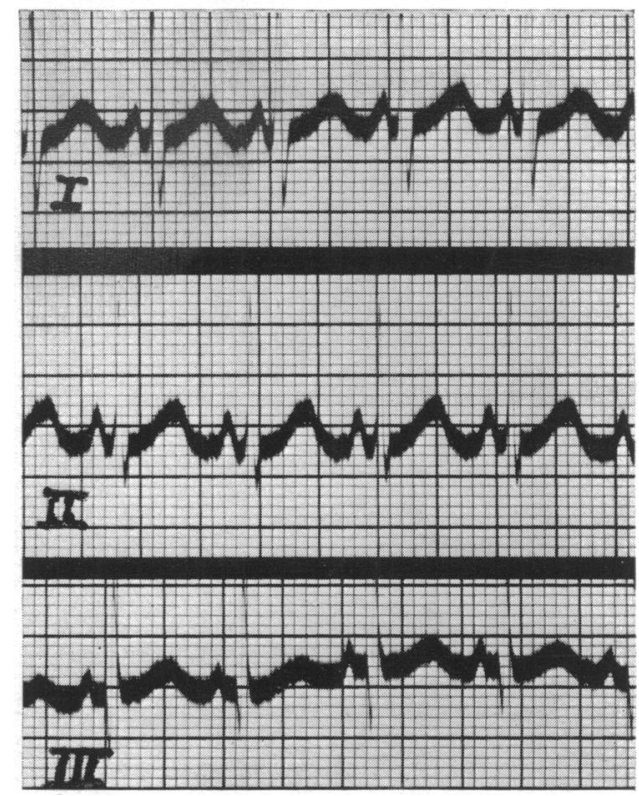

FIG. 2.-Electrocardiogram taken 12 hours after second dose of pronestyl, showing return of sinus rhythm.

\section{Discussion}

Procaine amide, the synthetic analogue of procaine, has been found to have potent anti-arrhythmic properties. Its action is not, as yet, fully understood, although it is known to have an effect similar to that of quinidine and prolongs the refractory period of heart muscle. Kayden et al. (1951) recommended intravenous administration in adults at a rate of $200 \mathrm{mg}$. a minute until a total of $1 \mathrm{~g}$. has been given, while orally a single dose of $1.25 \mathrm{~g}$. followed by $0.75 \mathrm{~g}$. in one hour was effective. McCord and Taguchi (1951) have employed this drug in three cases of paroxysmal supraventricular tachycardia with reversal to normal sinus rhythm in each case, while Berry et al. (1951) have had good results in 22 cases of nodal and auricular tachycardia with only 4 failures. More recently, serious toxic effects have been reported following the use of pronestyl, and Read (1952) reported a death from ventricular tachycardia in a woman of 61 years after an intravenous dose of $\mathbf{2 0 0} \mathrm{mg}$., while pyrexia and a macular rash have also been reported by Bakos and Askey (1952) and Hellman (1952). Digoxin and pronestyl are equally successful in the treatment of paroxysmal tachycardia, but if any advantage can be claimed for pronestyl, it is its rapidity of action, which is almost immediate, while the first effects of digoxin are not noted for about two to four hours. The dose of procaine amide in infants is not known, but in the case reported 110-132 mg. per kg. body weight was effective. It is possible that if a larger dose of pronestyl had been given at the outset, one intravenous injection only might have been necessary. It is interesting to note that the pronestyl had no effect in lengthening the P-R interval or the Q-T interval. Further trials with this drug must be carried out before its place in the treatment of the cardiac arrhythmias can be assessed and future developments are awaited with interest.

\section{Summary}

A case of paroxysmal supraventricular tachycardia in infancy is described. Two intravenous doses of procaine amide hydrochloride totalling $125 \mathrm{mg}$. brought the paroxysm to an end.

I am grateful to Dr. W. H. Patterson, Medical Superintendent, Booth Hall Hospital, for his advice.

\section{REFERENCES}

Bakos, A. C. P., and Askey, J. M. (1952). J. Amer. med. Assoc., 149, 1393.

Berry, K., Garlett, E. M., Bellet, S., and Gefter, W. I. (1951). J. Amer. Med., 43, 1.

Hellman, E. (1952). J. Amer. med. Assoc., 149, 1393.

Kayden, H. J., Steel, J. M., Mark, L. E., and Brodie, B. B. (1951). Circulation, 4, 13.

McCord, M. A., and Taguchi, J. H. (1951). Circulation, 4, 387.

Read, J. M. (1952). J. Amer. med. Assoc., 149, 1390. 